radially, and that no mesenteries have been seen." Mr. Moseley was naturally dissatisfied with these poor results, and hoped to do better things at $\mathrm{Hawaii}$. In the meantime I became aware of the value of the drawings I have already alluded to, and as I am at work on several subjects with Gen. Nelson, I sent a communication and the drawings to the "Annals and Magazine of Natural History" before the evening of April 6, when Mr. Moseley's paper on Millepora was heard by me at the Royal Society. It is a satisfaction for me to be able to state that Gen. Nelson's drawings prove that Agassiz saw a part of a polype, and that Mr. Moseley's beautiful delineations, far in advance of all, testify to the correctness of my fellow-worker. I do not credit the hydroid nature of the polyp now, any more than I did when writing the reports on the British fossil corals, and I believe Millepora to be an Actinozoan.

\section{P. Martin Duncan}

\section{The Use of the Words "Weight" and "Mass"}

THE relations between weight and mass, gravity and acceleration, are so well defined in all good treatises on dynamics, that it appears superfluous to dwell on these questions. But as it has been stated by Prof. Harrett, vol. xiii., p. $3 \delta 5$, that the C. G. S. system of units has been introduced into the course of Mechanics in this College, I may be permitted to say that the system actually employed is not that referred to by your correspondent. I generally employ the kilogranme, metre, and second, and sometimes the foot, pound, and second, to measure a dynam or unit of force. The dynamometers alluded to as about to be exhîbited at the Loan Exhibition of Scientific Instruments at South Kensington are suitable to the former system, and I use them for the measurement of dynams in kilogrammetres. One of these dynamometers is graduated for every 200 grammes up to roo kilogrammes, the other for every I0o grammes up to Io kilogrammes, and they cannot be depended on for results within the tenth of a kilogramme. Spring dynamometers, though suitable for the large units employed in mechanics, are totaily unfit for measuring units on the C. G. S. system. I concur with Prof. Everett, in his book on this system, when he says:-" A spring balance, it is true, gives a direct measurement of force, but its indications are too rough for purposes of accuracy" (p. 8). Spring dynamometers are therefore unsuited to a system where the units are measured by $\frac{1}{95} \mathrm{r}$ of a gramme, or about $\frac{1}{63}$ of a grain, as in the C. G. S. system.

Royal College of Science for Ireland, Dublin

\section{The Physical Constitution of Steam}

I JELIEVE the following remarks on the physical constitution of steam are in some degree original, in form at least, though perliaps not in substance.

Dr. Andrews has shown by his experimental researclies on carbonic acid, that at a temperature above $31^{\circ} \mathrm{C}$. or $88^{\circ} \mathrm{F}$. the difference between the gaseous and the liquid states no longer exists. I quote the following brief statement from an admirable paper on the subject, by Prof. James Thomson, in the "Proceedings of the Belfast Natural History and Philosophical Society, "1872; - he is speaking of the case in which a given quantity of carbonic acid, of which part is in the gaseous and part in the liguid state, is kept at constant volume, while the temperature, and consequently the pressure, are gradually increased :-

"As the temperature and pressure are augmented, the gaseous part is always increasing in density, and the liquid part is diminishing in density, till at last the two come to have the same density with one another, and then they are perfectly alike in every respect, all distinction between them having vanished. At this stage the temperature is $3 \mathrm{I}^{\circ} \mathrm{C}$., and the pressure is about seventy-five atmosplieres. Above this temperature of $31^{\circ}$ no change of pressure can cause gasification or liquefaction ; and above this pressure of about severty-five atmospheres, no cliange of temperature can cause gasification or liquefaction."

This temperature of $3 \mathrm{I}^{\circ} \mathrm{C}$. is called by Dr. Andrews the critical temperature for carbonic acid. Above its critical temperature, although carbonic acid may have the density either of a gas or of a liquid, the two states are not sharply separated from each other as a liguid is from is vapour, but graduate into each other insensibly. It is believed that every gas and vapour has its own critical temperature. Those of the permanent gases are believed to be so low as to be unattainable by any known process. That of water or steam, on the contrary, is probably too high to be observed in a glass tube, and consequently too high to be directly observed at all : for the only known test of the critical tempera. ture being attained, consists in the disappearance of the visible boundary surface between the liquid and the vapour or gas. My purpose is to show how the critical temperature for steam may be approximately estimated with a great degree of probability.

The fact that the latent heat of steam diminishes as the temperature increases, formerly seemed to me one of the strangest of all facts ; but the above-mentioned properties of carbonic acid, and no doubt of all gases and vapours, make it quite intelligible.

The latent heat is defined as the heat given out when steam is condensed into water of its own temperature. The total heat is defined as the heat given out when steam is condensed into water at zero Centigrade, and is the sum of the latent heat and the temperature. According to Regnault, the relation between temperature and total heat is expressed by the fornula-

$$
\lambda=606 \cdot 5+305 t \text {. }
$$

$\lambda$ being the total heat and $t$ the temp-rature. This has been ascertained to be true from $0^{\circ}$ to $230^{\circ}$, and if it is true for all temperatures, at a temperature of $872 \cdot 7$ the total heat and the temperature would be the same, and the latent heat would vanish : 8727 is consequently the critical temperature which is deducible from the above formula for water.

Old Forge, Dunmurry, JOSERH JOHN MURPhY Co. Antrim

\section{Coloured Solar Halos}

IN the interesting letters of Drs. Schuster and Frankland I note some remarks on the rarity of the apparition of complete halos about the sun in this country. Had I read these remarks some six years ago I should have passed them by without surprise. It so happened, however, that my attention was drawn to the subject of halos, coronas, \&c., by Kämtz's ' Lehrbuch der Meteorologie" about the year 1869 , and I at once began to examine the sky near the sun every fine day, and note down any appearance of halos, fringes, \&c. When I began, my impression was that I should rarely see the solar halo seeing that it had escaped me for several years. However, I soon found out my mistake, and the subjoined list, compiled from the observatory note-books, gives the number seen each month in 1874 and 1875 . No doubt, several escaped my vigilance in some months and a few in others. The figures, at any rate, show that the phenomenon is by no means rare.

$$
\text { Solar Halos in } 1874 \text { and } 1875 \text {. }
$$

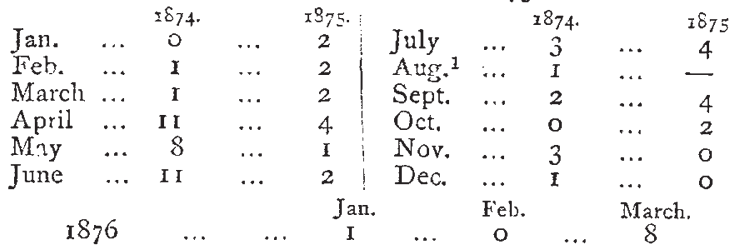

Had I been quite sure that Dr. Schuster's remarks referred to the ordinary solar halo, this letter would have reached you a week ago or more. I will only add that the halos I have observed are nearly always complete (when the sun is high enough), that they are often very bright and most striking phenomena, and that the radius is usually about $22^{\circ}$.

Bermerside, Halifax, April 6

Joseph Gledhill

\section{"The Effect of the Sun's Rotation and the Moon's Revolution on the Earth's Magnetism"}

THE above was the title of an articie by J. Allan Broun, published in NATURE, vol. xiii. p. 328 .

The establishment of these facts, if they have not already been I tublished, will aid amateur investigators very much in arriving at satisfactory conclusions in regard to the phenomenon above referred to.

First, from the revolutions of the sun, do the positively defined edges of sumspots always reappear at the same moment, and are their relative positions with regard to each other ever the same through a series of years, giving them a fixed and positive character, both as to position and time of revolution?

Second: At what times, with regard to the position and area of the largest and most numerous sunspots, and whether they are hidden by the revolution of the sun, or face the earth, is the I I was from home most of this month in both years. 